\title{
Reducing intrathecal baclofen related infections: service evaluation and best practice guidelines
}

Michelle Balaratnam ${ }^{1,2}$, Ann Donnelly ${ }^{1}$, Honey Padilla ${ }^{1}$, Sara Simeoni ${ }^{1}$, Sardar Bahadur ${ }^{1}$, Liz Keenan ${ }^{1}$, Heesook Lee ${ }^{1}$, Rachel Farrell ${ }^{1,2}$, Carmel Curtis ${ }^{1}$, Robert Brownstone ${ }^{1,2}$, Mary Murphy ${ }^{1}$, Joan Grieve $^{1}$, Colin Shieff ${ }^{1}$, Meenakshi Nayar ${ }^{1}$, Robert Pitceathly ${ }^{1,3}$, Gerry Christofi ${ }^{1}$, Valerie Stevenson ${ }^{1}$

${ }^{1}$ The National Hospital for Neurology and Neurosurgery, UCLH, Queen Square, London WC1N 3BG United Kingdom

${ }^{2}$ UCL Institute of Neurology, Queen Square, London WC1N 3BG United Kingdom

${ }^{3}$ MRC Centre for Neuromuscular Diseases, UCL Queen Square Institute of Neurology, London WC1N 3BG United Kingdom

Corresponding author: Michelle Balaratnam

Email m.balaratnam@nhs.net

Key words: Spasticity, Intrathecal Baclofen, Multiple Sclerosis, Cerebral Palsy, Acquired Brain Injury Word count (excluding title page, abstract, references, figures and tables): 1782

References: 20 


\section{Abstract:}

\section{Objectives:}

Intrathecal baclofen (ITB) pumps are an effective treatment for spasticity; however infection rates have been reported in $3-26 \%$ of patients in the literature. The multidisciplinary ITB service has been established at UCLH, Queen Square, London for over 20 years. Our study was designed to clarify the rate of infection in our ITB patient cohort and secondly, to formulate and implement best practice guidelines and to determine prospectively, whether they effectively reduced infection rates.

\section{Methods:}

Clinical record review of all patients receiving ITB pre-intervention; January 2013 - May 2015, and following practice changes; June 2016 - June 2018.

\section{Results:}

Four of 118 patients receiving ITB during the first time period (3.4\%, annual incidence rate of infection 1.4\%) developed an ITB-related infection (3 following replacement surgery, one after initial implant). Infections were associated with $4.2 \%$ of ITB-related surgical procedures. Three of four pumps required explantation.

Following change in practice (pre-operative chlorhexidine skin wash and intra-operative vancomycin wash of the fibrous pocket of the replacement site), only one of 160 ITB patients developed infection (pump not explanted) in the second time period $(0.6 \%$, annual incidence rate $0.3 \%)$. The infection rate related to ITB surgical procedures was $1.1 \%$. In cases of ITB pump replacement, the infection rate was reduced to $3.3 \%$ from $17.6 \%$.

\section{Conclusions:}

This study suggests that a straightforward change in clinical practice can lower infection rates in patients undergoing ITB therapy. 
Reducing intrathecal baclofen related infections: service evaluation and best practice guidelines.

Balaratnam MS, Donnelly A, Padilla H, Simeoni S, Bahadur S, Keenan L, Lee H, Farrell R, Curtis C, Brownstone RM, Murphy M, Grieve J, Shieff C, Nayar M, Pitceathly RDS, Christofi G, Stevenson VL.

\section{Introduction:}

Spasticity is a common consequence of neurological conditions and causes discomfort, stiffness and spasms. If inadequately treated, it can contribute to contractures and/or pressure ulcers $^{1,2}$. Intrathecal baclofen (ITB) delivery via an implanted pump is an effective treatment for the management of spasticity in many conditions, including cerebral palsy, multiple sclerosis, traumatic brain injury, stroke, and spinal cord injury ${ }^{3,4,5}$.

Patients requiring ITB therapy are usually wheelchair users. However, increasingly ITB therapy is utilised to improve walking and minimise muscle shortening and contractures ${ }^{4}$. ITB therapy is not without risks. Infection rates have been reported in $3-26 \%$ of patients, ${ }^{3,6,7,8,9,10}$ with higher rates reported following pump replacements versus first implants, and higher in children than adults.

The multidisciplinary ITB service has been established at UCLH, London for over 20 years ${ }^{11}$ and is currently responsible for 160 adult patients. Two thirds have multiple sclerosis, with the remainder having a variety of conditions (Figure 1). In May 2015, we were alerted to two pump-related infections prompting a review of our infection rates. 


\section{Aims:}

Firstly, to clarify the rate of ITB related infections, possibly identifying factors that may increase the risk of infection. Secondly, to formulate and implement best practice guidelines and to determine, during a prospective follow up period, whether they effectively reduced infection rates.

\section{Methods:}

A retrospective review of clinical records was undertaken, including all patients under the service during two time periods: pre-intervention; January 2013 to May 2015, and following practice changes; June 2016 to June 2018. Baseline patient characteristics (age, gender, diagnosis), the details of any surgical procedures performed and any ITB-related infections were recorded for all patients.

ITB-related infections were defined if any of the following were present: 1) clinical suspicion of infection around ITB hardware (e.g. skin redness, swelling, purulent discharge); 2) microbiological evidence of infection from swab culture; 3) fever or rise in inflammatory markers. At each respective time period the infection rate was calculated in relation to both the number of patients with ITB pumps under our care and the number of ITB-related surgical procedures undertaken. Factors contributing towards infections, including patient's weight, diabetes, immunodeficiency, pressure ulcer, systemic illness, smoking, pre-operative MRSA status, surgeon, antibiotics at induction of surgery, length of surgery, and theatre location, were investigated. 


\section{Statistical Analysis:}

The comparison between groups was compared with a Fisher exact test using a $2 \times 2$ contingency table. A p value $\leq 0.05$ was considered significant.

\section{Institutional Approval:}

The audit was registered with the Clinical Governance Audit Committee at UCLH. No additional data to routine care was collected.

\section{Results:}

\section{Review 1: Retrospective series (2013 - 2015):}

The number of patients and surgical procedures are detailed in Table 1. Of the 118 patients receiving ITB during this time period, 75 were admitted for a total of 95 surgical procedures. 60 of these procedures were planned (43 new ITB pump implants, 17 pump replacement surgeries for end of battery life). Details of surgical procedures are in Table 2.

We identified four ITB-related infections in four patients $(3.4 \%, 4 / 118$ of ITB patients, annual incidence rate of infection 1.4\%). ITB-related infections occurred on average 27 days (range 14-49 days) after an ITB-related surgical procedure. Three of these cases occurred following routine pump replacements and one occurred after first ITB pump implantation. The case after first implantation occurred in an individual who was admitted to his local hospital with chest sepsis, and subsequently developed a wound ooze in the context of MRSA septicaemia. Infections were associated with $4.2 \%$ (4/95) of all ITB-related surgical procedures undertaken during this period. All ITB-related infections occurred at the abdominal (pump) surgical site, rather than the lumbar (ITB catheter) surgical site. Following 
ITB pump replacement surgery the infection rate was $17.6 \%(3 / 17)$. All infections were treated with intravenous antibiotics. Three ITB pumps were explanted, and one superficial infection following pump replacement surgery was successfully treated without need for explantation.

Weight, diabetes, immunodeficiency, skin conditions, systemic illness and smoking are known to increase risk of infection in hardware implantation ${ }^{12}$. The only possible factor identified in our infection cases was the presence of a pressure ulcer (grade $>1$ ) on admission in two of the four patients with ITB-related infection. However, an additional ten patients with pressure ulcers were admitted for ITB-related surgical procedures during the time period and did not develop an ITB-related infection $(p=0.08 ; 95 \% \mathrm{Cl}-0.01-0.47)$. All patients routinely received a single dose of intravenous cefuroxime (or teicoplanin if penicillin allergic) at induction of the surgical procedure. Microbiological analysis of the four individuals' ITB wound culture confirmed growth of a Gram positive organism in each patient (Staphylococcus capitis, Staphylococcus aureus, methicillin resistant Staphylococcus aureus, Corynebacterium striatum respectively). Consequently, we considered whether the choice of antibiotic at induction was optimal and whether the fibrous pocket around the ITB pump site prevented penetrance of the intravenous prophylactic antibiotics prior to ITB replacement surgery. A similar hypothesis has already been described in the deep brain stimulation (DBS) literature ${ }^{12,13}$. Our routine practice for ITB pump replacements involved opening the original abdominal scar and washing out the fibrous pocket with saline, prior to implanting the replacement pump. Based on published experience in the DBS literature we made the following recommendations. 
Table 1: Changes in practice following the retrospective series:

\begin{tabular}{|c|c|c|}
\hline Recommended practice & $\begin{array}{l}\text { Origin of recommended } \\
\text { practice }\end{array}$ & References and comment \\
\hline $\begin{array}{l}\text { Pre-operative practices } \\
\text { Utilisation of a single skin } \\
\text { chlorhexidine wash }(4 \%) \text { on } \\
\text { the day of surgery }\end{array}$ & CDC 1A & $\begin{array}{l}\text { This is the practice used in } \\
\text { our centre in patients } \\
\text { undergoing DBS. Halpern } \\
\text { and colleagues } \\
\text { demonstrated a reduction of } \\
\text { infections following DBS } \\
\text { surgery }{ }^{14} \\
\text { Kohler and colleagues } \\
\text { demonstrated that Mupirocin } \\
\text { and antiseptic body wash } \\
\text { may reduce superficial but } \\
\text { not deep surgical site } \\
\text { infections }{ }^{15} \text {. }\end{array}$ \\
\hline $\begin{array}{l}\text { Application of an occlusive } \\
\text { dressing to pressure sores }\end{array}$ & CDC $1 \mathrm{~B}$ and NICE & $\begin{array}{l}\text { Hutchison and colleagues } \\
\text { demonstrated lower rates of } \\
\text { infection with occlusive } \\
\text { dressings }^{16}\end{array}$ \\
\hline $\begin{array}{l}\text { Intraoperative practices } \\
\text { A vancomycin wash was } \\
\text { used within the implant } \\
\text { pocket (20ml of } 1 \mathrm{mg} / \mathrm{ml} \\
\text { vancomycin solution) for all } \\
\text { ITB pump replacement } \\
\text { surgeries. }\end{array}$ & & $\begin{array}{l}\text { Pepper and colleagues had } \\
\text { previously demonstrated a } \\
\text { vancomycin wash to be } \\
\text { effective in reducing the rate } \\
\text { of infection in DBS patients }{ }^{13} \text {. }\end{array}$ \\
\hline
\end{tabular}


CDC, centers for disease control; NICE, National Institute for Health and Care Excellence; SCIP, Surgical Care Improvement Project of the Joint Commission; SSIs, surgical site infections.

CDC recommendations. IA: Strongly recommended for implementation and supported by well-designed experimental, clinical, or epidemiological studies. IB: Strongly recommended for implementation and supported by some experimental, clinical, or epidemiological studies and strong theoretical rationale. II: Suggested for implementation and supported by suggestive clinical or epidemiological studies or theoretical rationale.

\section{Review 2: Second series Re-evaluation following changes to practice (2016-2018):}

Following the change in practice, there was one case of ITB-related infection. This occurred 26 days after a routine ITB pump replacement, in a gentleman who had several areas of skin breakdown of grade 2 or more. The patient presented with abdominal swelling and erythema at the operative site. The site was aspirated and no growth was seen on cultures. The infection settled with intravenous teicoplanin and the ITB pump was preserved. Therefore, ITB-related infections in the ITB population reduced from $3.4 \%(4 / 118)$ in the first series to $0.6 \%(1 / 160)$ in the second series $(p=0.17 ; 95 \% \mathrm{Cl}-0.01-0.08)$. The annual incidence rate of infection in the second series was $0.3 \%$. The infection rate related to ITB surgical procedures reduced from $4.2 \%(4 / 95)$ in the first series to $1.1 \%(1 / 91)$ in the second series $(p=0.37 ; 95 \% \mathrm{Cl}-0.03-0.1)$. In cases of ITB pump replacement, the infection rate reduced from $17.6 \%(3 / 17)$ to $3.3 \%(1 / 30)(p=0.13 ; 95 \% \mathrm{Cl}-0.06-0.41)$. After the change in practice, no ITB pumps were explanted due to infection.

\section{Adverse events}

There were no adverse events observed in relation to the topical chlorhexidine wash or intraoperative vancomycin wash during the time period investigated.

\section{Discussion:}

ITB-related infection is potentially a serious complication and can result in deep-seated infection and meningitis ${ }^{7}$. Patient and carer education is essential to identify suspected infection cases and seek medical attention early. However, despite this, the noted rate of 
infection is $3-26 \%$ (literature), and in our series prior to adaptation, $3 / 17$ (17.6\%) patients undergoing pump replacements required explantation due to ITB-related infection. There were no cases of serious baclofen withdrawal. Of note, patients who suffered infective complications did not want their pump removed highlighting the positive impact of ITB therapy on symptom management; all were re-implanted once the infection was treated and wound healed.

In the initial retrospective series, ITB-related infections occurred in $3.4 \%$ of all patients with ITB pump implants and $4.2 \%$ of all ITB-related surgeries. This is in line with the published rates of infection in $3 \%-26 \%$ of cases $^{3,6,7,8,9,10}$. ITB pump replacement surgery is an elective procedure due to end of battery life (6-7 years). In common with published series, our infection rate was higher following ITB pump replacement procedures than first pump implants $3,6,7,8,9,10$. Similarly, increased risk of infection after replacement procedures has also been observed in other implantable devices, such as DBS and cardiac pacemaker battery replacement ${ }^{12,13,17}$. As in those cases, we hypothesised that this was most likely due to reduced vascular flow in the fibrous pocket.

Pressure sores, urinary tract infections and immunomodulatory medications are perhaps more common in the multiple sclerosis cohort than in a spinal cord injury population so a higher rate of infection may have been expected in these patients. However, despite the significantly higher proportion of patients with multiple sclerosis in our patient cohort (Figure 1), in the first series only two out of the four infection cases were in patients with multiple sclerosis. The remaining two infection cases had traumatic brain injury and hereditary spastic paraplegia respectively. The infection case in the second series was in a patient with a vascular malformation. Therefore, the measures taken to reduce risk of infection would be equally applicable to a more general population. 
Our change in practice was associated with a reduced rate of ITB-related infections and no further ITB pumps were lost in the follow-up period. We have attributed this to the use of the vancomycin wash. We acknowledge that Ghobrial and colleagues failed to demonstrate a reduction in infections following intrathecal baclofen procedures with the use of vancomycin powder ${ }^{18}$. However, more recently Thompson and colleagues and Tailaiti and colleagues have demonstrated a reduction in surgical site infections with the use of vancomycin powder $^{19,20}$. In the case of the ITB replacements, it is possible that the turbulence generated with a "washout" as in our method, is more effective than instilling vancomycin powder. It is also possible that the vancomycin in solution is more effective and perhaps more evenly distributed than the powder, to account for our results, compared to the results of Ghobrial and colleagues.

The reduction in infections reflected a small number of patients in the two time periods (four cases of infection in the retrospective series versus one in the second series). However, the reduction in proportion of infections in the ITB replacement surgeries appeared more substantial as the number of elective replacement surgeries was larger in the second time period (17 versus 30 replacement procedures, respectively). This reflected the growth of our service and increased number of routine ITB replacements undertaken for end of battery life. Despite the small numbers preventing our data reaching statistical significance, the reduction in ITB-related infections is meaningful for our patient cohort. The coexistence of a pre-existing pressure ulcer and subsequent wound infection is interesting and perhaps highlights the need for extra caution in patients with pressure ulcers. 


\section{Conclusions:}

- ITB-related infections were associated with an ITB-related surgical procedure, rather than de novo infections in the ITB community in the time periods investigated.

- ITB-related infections were more common after a routine pump replacement than first implantation.

- Following implementation of a change in practice, including a pre-operative chlorhexidine skin wash and an intra-operative vancomycin wash of the fibrous pocket of the replacement site, there was a reduction in ITB-related infection after pump replacement surgeries.

- This study suggests that a straightforward change in clinical practice may lower infection rates in patients undergoing ITB therapy.

Figure 1. Underlying neurological condition of our patient cohort

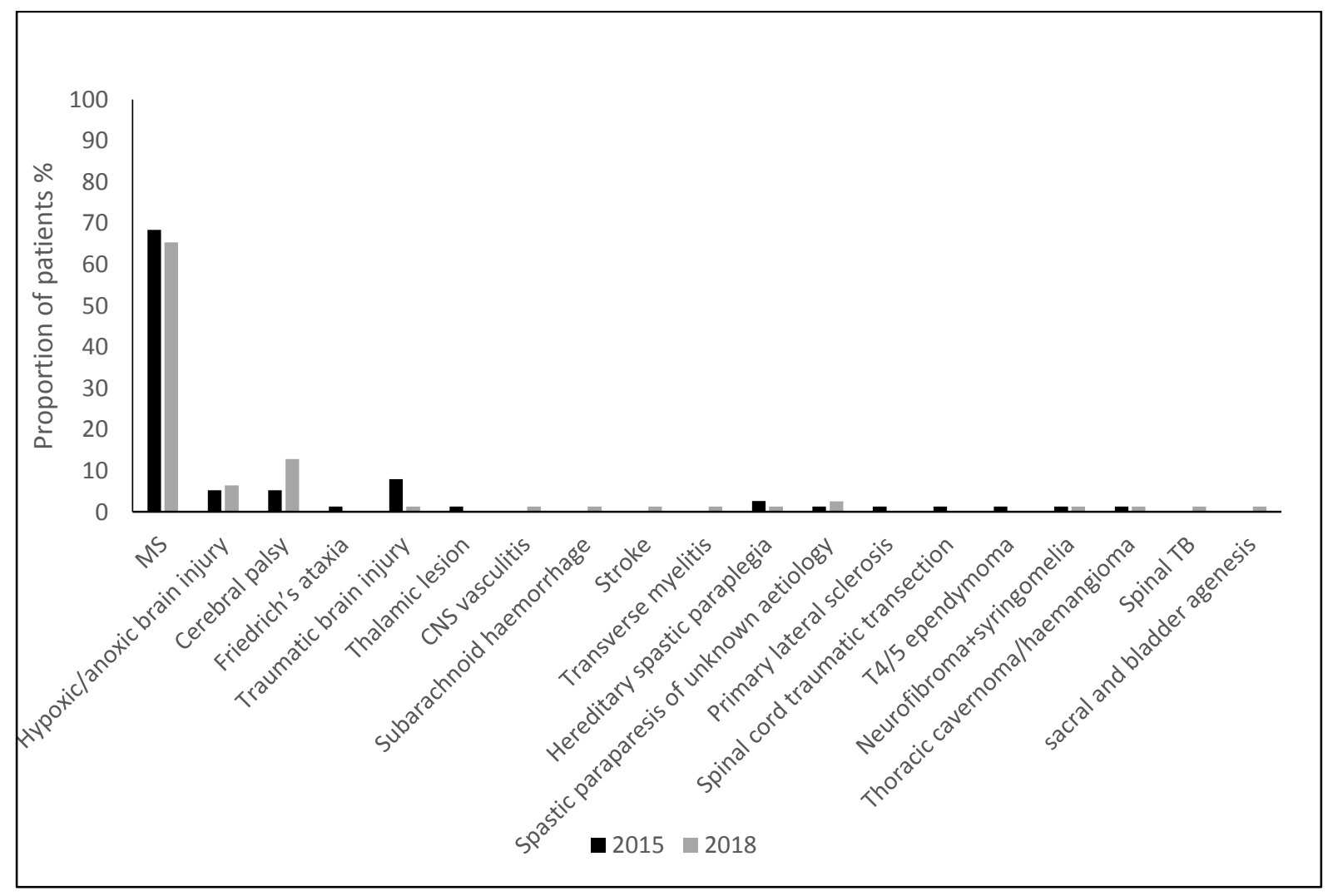


Table 2. Number of patients and surgical procedures

\begin{tabular}{|c|c|c|c|c|c|c|c|}
\hline Time period & $\begin{array}{c}\text { Number } \\
\text { of } \\
\text { patients } \\
\text { having } \\
\text { ITB } \\
\text { therapy }\end{array}$ & $\begin{array}{c}\text { Average } \\
\text { age }\end{array}$ & $\begin{array}{c}\text { Total } \\
\text { number of } \\
\text { ITB- } \\
\text { related } \\
\text { surgical } \\
\text { procedure }\end{array}$ & $\begin{array}{l}\text { Number of } \\
\text { new ITB } \\
\text { surgeries }\end{array}$ & $\begin{array}{l}\text { Number of } \\
\text { ITB pump } \\
\text { replacemen } \\
\text { ts }\end{array}$ & $\begin{array}{l}\text { Number of } \\
\text { catheter } \\
\text { revisions/siti } \\
\text { ng }\end{array}$ & $\begin{array}{c}\text { Number of non- } \\
\text { elective ITB pump } \\
\text { surgeries }\end{array}$ \\
\hline $\begin{array}{c}2013- \\
2015 \\
\text { (29 months) }\end{array}$ & 118 & $\begin{array}{c}45.9 \\
\text { years } \\
\text { (range } \\
22-79 \\
\text { years) }\end{array}$ & 95 & 43 & 17 & 29 & $\begin{array}{l}3 \text { ITB pump removed } \\
\text { due to infection } \\
1 \text { ITB pump no longer } \\
\text { needed } \\
2 \text { ITB pump resited } \\
\text { due to flip/vulnerable }\end{array}$ \\
\hline $\begin{array}{c}2016- \\
2018 \\
\text { (24 months) }\end{array}$ & 160 & $\begin{array}{c}46.8 \\
\text { years } \\
\text { (range } \\
17-73 \\
\text { years) }\end{array}$ & 91 & 41 & 30 & 10 & $\begin{array}{l}0 \text { removed due to } \\
\text { infection } \\
3 \text { no longer needed } \\
6 \text { ITB pump resited } \\
\text { due to flip/vulnerable } \\
1 \text { haematoma } \\
\text { evacuation at pump } \\
\text { site }\end{array}$ \\
\hline
\end{tabular}




\section{References:}

1. Thompson AJ, Jarrett L, Lockley L, et al. Clinical management of spasticity. Journal of Neurology, Neurosurgery \& Psychiatry 2005;76:459-463

2. Kheder A, Nair KP. Spasticity: pathophysiology, evaluation and management. Prac Neurol 2012; 12: $289-298$

3. Natale M, Mirone G, Rotondo M, Moraci A. Intrathecal baclofen therapy for severe spasticity: Analysis on a series of 112 consecutive patients and future prospectives. Clin Neurol Neurosurg 2012;114(4):321-5.

4. Margetis $\mathrm{K}$, Korfias $\mathrm{S}$, Boutos $\mathrm{N}$ et al. Intrathecal baclofen therapy for the symptomatic treatment of hereditary spastic paraplegia. Clin Neurol Neurosurg 2014; $123: 142-5$.

5. Schiess MS, Oh IJ, Stimming EF et al. Prospective 12 month study of intrathecal baclofen therapy for post stroke spastic upper and lower extremity motor control and functional improvement. Neuromodulation 2011; 14(1): 38 - 45

6. Albright AL, Turner M, Pattisapu JV. Best practice surgical techniques for intrathecal baclofen therapy. J Neurosurg 2006;104(4 Suppl):233-9

7. Vender JR, Hester S, Waller JL, Rekito A, Lee MR. Identification and management of intrathecal baclofen pump complications: A comparison of pediatric and adult patients. J Neurosurg 2006;104(1 Suppl):9-15.

8. Dickey MP, Rice MSM, Kinnett DG et al. Infectious complications of intrathecal baclofen pump devices in a pediatric population. Pediatr Infect Dis J 2013;32(7):71522

9. Ghosh D, Mainali G, Khera J, Luciano M. Complications of intrathecal baclofen pumps in children: Experience from a tertiary care center. Pediatr Neurosurg 2013;49(3):138-44. 
10. Motta F, Antonello CE. Analysis of complications in 430 consecutive pediatric patients treated with intrathecal Baclofen therapy: 14 year experience. J Neurosurg Pediatrics 2014;13:301-306.

11. Sammaraiee Y, Yardley M, Keenan L, Buchanan K, Stevenson V, Farrell R. Intrathecal baclofen for multiple sclerosis related spasticity; A twenty year experience. Mult Sclero Relat Disord 2018;27:95-100.

12. Pepper J, Zrinzo L, Mirza B, Foltynie T. The risk of hardware infection in deep brain stimulation surgery is greater at impulse generator replacement than at the primary procedure. Stereotact Func Neurosurg 2013;91:56 -65

13. Pepper J, Meliak L, Akram H, Hyam J, Milabo C, Candelario J, Foltynie T, Limousin P, Curtis C, Hariz M, Zrinzo L. Changing of the guard: reducing infection when replacing neural pacemakers. J Neurosurg 2017;126(4):1165 - 1172.

14. Halpern C, Mitcheel G, Paul A et al. Self administered preoperative antiseptic wash to prevent post-operative infection after deep brain stimulation. Am J Infect Control $2012 ; 40: 431-433$.

15. Kohler P, Sommerstein R, Scheonrath $\mathrm{F}$ et al. Effect of perioperative mupirocin and antiseptic body wash on infection rate and causative pathogens in patients undergoing cardiac surgery. Am J Infect Control 2015;43:e33-e38

16. Hutchison JJ, McGuckin M. Occlusive dressings: a microbiologic and clinical review. Am J Infect Control 1990;18:257-268

17. Gould PA, Krahn AD. Canadian Heart Rhythm Society Working Group on Device Advisories: Complications associated with implantable cardioverter-defibrillator replacement in response to device advisories JAMA 2006; 295:1907-1911.

18. Ghobrial GM, Thakkar V, Singhal S, Oppenlander ME, Maulucci CM, Harrop JS, Jallo J, Prasad S, Saulino M, Sharan AD. J Clin Neurosci. 2014;21(10):1786-9.

19. Thompson GH, Poe-Kochert C, Hardesty CK, Son-Hing J, Mistovich RJ. Does Vancomycin powder decrease surgical site infections in growing spine surgery?: A preliminary study. J Bone Joint Surg Am, 2018:100(6):466-471. 
20. Tailaiti A, Shang J, Shan S, Muheremu A. Effect of intrawound vancomycin application in spinal surgery on the incidence of surgical site infection: a metaanalysis. Ther Clin Risk Manag, 2018;14:2149-2159 